\title{
学会賞受賞記念寄稿
}

\section{Quantitative Precipitation Estimation and Hydrological Modeling in Japan}

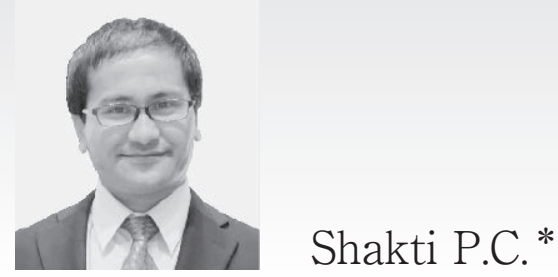

\section{Introduction}

The Japan Society of Hydrology and Water Resources (JSHWR) nominated me for the Young Author Excellent Paper Award (2016) during their annual meeting held on September 14-16, 2016 in Fukushima, Japan. I extend my sincere thanks to Prof. Tadashi Yamada, President of JSHWR, and the Advisory Committee for nominating me for this award. I feel privileged and grateful to have received such a prestigious award, and my nomination motivates me to further advance the field of hydrology and water resources. I would like to make a special mention of Prof. Masayuki Maki, Kagoshima University, Kagoshima, Japan. He supervised my PhD at the Graduate School of Life and Environmental Sciences, University of Tsukuba, Japan, and I am very appreciative of his generosity, continuous mentorship, and advice. The support of Prof. Masayuki and his family have helped to develop my research career throughout my stay in Japan.

Since completing my PhD in 2013 I have been working as Associate Research Fellow at the Storm, Flood and Landslide Research Division of the National Research Institute for Earth Science and Disaster Resilience (NIED). Although I am the one standing here accepting this honor, the award belongs equally to the great teams that I have worked with at various stages of my career. Therefore, my sincere thanks go to Drs. Ryohei Misumi, Tsuyoshi Nakatani, Koyuru Iwanami, Shin-ichi Suzuki, Takeshi Maesaka, Shingo Shimizu, Kohin Hirano, Namiko Sakurai, Yukari Shusse, Kaori Kieda, Ken-ichi Shimose, Ryohei Kato, and other staff at the NIED for their encouragement and contributions to my research. Special thanks also go to Dr. Toshi Nakaegawa, chief editor of Hydrological Research letters, for working closely with us during the preparation and submission of our manuscript.

I was born in Sandhikharka-6, Arghakhanchi, a remote, beautiful, and mountainous area of western Nepal. Growing up there, I developed an interest in the yearly monsoon rainfalls and floods. After graduating from Tribhuvan University, Kathmandu, Nepal, I moved to Belgium to study in the Interuniversity Program in Water Resources Engineering (IUPWARE). After completing my master's degree, I relocated to Japan in 2010 to begin my PhD at the University of Tsukuba under the supervision of Prof. Masayuki Maki. Since graduating in 2013, I have been working at NIED on a range of different projects. My research has focused on radar-based quantitative precipitation estimation (QPE) and precipitation nowcasting, which are important components of systems that aim to minimize or manage flash flooding. I believe that this research makes a creative contribution to progress in the field of hydrology and meteorology, and I am proud that my work has been recognized by JSHWR.

Previous research has demonstrated that the number of flood-affected populations could increase in the future

\footnotetext{
* Associate research fellow, Storm, Flood and Landslide Research Division, National Research Institute for Earth Science and Disaster Resilience(NIED)
} 
(Hirabayashi and Kanae, 2009; Maki et al., 2012b). Moreover, the rainfall that causes these flood events is becoming more variable and extreme, leaving many countries at greater risk from flood damage (Georgakakos, 2006; Kobiyama and Goerl, 2007). Traditionally, rain gauges have been used to measure precipitation in many parts of the world, and rainfall records are therefore available over long time periods (Strangeways, 2004). These data have been used in a range of applications, such as studies of water resources and agriculture. In general, spatial and temporal variations in precipitation are estimated using limited rain gauge networks and different interpolation methods. In many cases, interpolations do not always provide sufficiently precise rainfall distributions (Allegretti et al., 2012). Moreover, accurate estimates of precipitation rates are essential for monitoring and forecasting storm events, forecasting river discharge, evaluating water resources, managing hydrogeological risk, planning agricultural activities, analyzing flood frequency, quantifying and understanding the impacts of climate change, and assessing various other environmental phenomena (Berne et al., 2004; Germann et al., 2006). Precipitation can vary over a small area as a result of changes in natural topography and atmospheric circulation (Barros et al., 2000). Austin et al. (2002) showed, for example, that during a storm, rainfall may vary by tens of millimeters per hour, from minute to minute, and over distances of only a few tens of meters. For this reason, there has been a considerable interest in recent years in developing high spatial and temporal resolution gridded rainfall datasets (Chen et al., 2002; Mitra et al., 2003; Nesbitt and Anders, 2009; Price et al., 2014).

\section{Measurement of precipitation in Japan}

Approximately $80 \%$ of Japan is composed of hills and mountains. In ancient times, mountains were considered to be sacred by religious orders referred to as the Yamabushi (one who lives in the mountains). These orders believed that steep mountains were the dwelling places of gods, and that practicing ascetic disciplines in certain areas would allow them to develop holy and magical abilities. The highest mountain in Japan is the renowned Mt. Fuji (3,775 m), which is commonly known as Fujisan. Most rivers in Japan originate in mountainous terrain, and have been serving as a backbone of Japanese life, culture, and agriculture for centuries. Rivers in mountainous regions are unstable because of the steep, narrow river valleys and highly variable precipitation. Many urban areas in Japan, as well as forested nature reserves, are located near rivers that flow from the mountains. Therefore, accurate estimates of precipitation play a key role in predicting and managing disasters caused by precipitation in mountainous regions.

Precipitation is measured as the amount of water that reaches the Earth's surface, and is expressed as the vertical depth of water. In Japan, the unit used to measure precipitation is generally millimeters. Precipitation in Japan is delivered mainly by tropical cyclones, the Baiu frontal activity (formed by the monsoon circulation), and local convective systems. Average annual precipitation in Japan is $1,800 \mathrm{~mm}$, which is high compared with the global average of $970 \mathrm{~mm}$. Precipitation events sometimes result in serious disasters in Japan, such as floods and landslides. Studies have shown a nationwide over the past several decades (Fujibe et al., 2006). In recent times, rapid urbanization near mountains, the development of infrastructure alongside mountain rivers, and demands on water supply in mountainous regions have all been increasing. All of these changes are directly or indirectly linked to the characteristics of precipitation. Precipitationrelated disasters are common in mountainous regions because of their unstable geological structure. Moreover, the occurrence of narrow valleys surrounded by high relief makes disaster management in mountainous regions extremely difficult. Therefore, to minimize the risk of precipitation-induced disasters, there is a need to estimate or forecast temporal and spatial variations in the amount of precipitation over mountainous regions.

Measurement of precipitation began at the end of the $18^{\text {th }}$ century and there is now a long record of rainfall in some parts of Japan. Traditionally, rain gauges have been used to measure the amount of precipitation at a given location. Although rain gauges are the best available method of measuring precipitation, a dense network of observations stations is required to obtain accurate spatial and temporal precipitation patterns. Limited rain gauge networks are available in mountainous regions due to collecting precipitation data in mountainous regions is made difficult by the limited availability of rain gauge networks imposed by the remote locations, harsh physical environments, and the logistical problems and cost associated with maintaining and monitoring gauges. These limitations mean that important structures 
in precipitation fields may be missed in mountainous regions (Nesbitt and Anders, 2009).

Remote sensing technologies are the most common methods used to address the low density of precipitation stations in mountainous regions. Satellite observations can be used to monitor the spatial and temporal distribution of rainfall across a large domain. For example, the Global Satellite Mapping of Precipitation (GSMaP) project from the Japan Aerospace Exploration Agency (JAXA) Precipitation Measuring Mission (PMM) has produced a high-precision, high-resolution global precipitation map using satellite data and a rainfall algorithm. A comparison of the satellite-derived map with observational (station) data indicates large errors in precipitation derived from ground-based stations, especially for heavy and orographic rainfall (Kubota et al., 2009). As satellite derived rainfall has finer spatial and temporal resolution than ground-based data, it is used mainly for large-scale phenomena and long-term forecasting in Japan.

Different types of radar have also been used to record, monitor, and forecast precipitation in Japan for both operational and research purposes. The Japan Meteorological Agency (JMA) produces 1000-m spatial and 5-min temporal rainfall using more than $20 \mathrm{C}$-band radars (JMA radar) across Japan to provide real time operational data (Nagata, 2011). To minimize errors in rainfall estimates, JMA constantly updates data using limited Automated Meteorological Data Acquisition System (AMeDAS) gauge stations (Sugiura, 2013). The Ministry of Land, Infrastructure, Transport and Tourism (MLIT) established an X-band polarimetric radar network (XRAIN), which uses an operational data processing system developed by the National Research Institute for Earth Science and Disaster Prevention (NIED; Maki et al., 2005; Park et al., 2005; Maesaka et al., 2011). XRAIN is composed of X-band MP (multi-parameter) radars, and has spatial and temporal resolutions of 250-m and 1-min, respectively. This product is one of the best high-resolution radar rainfall systems in the world, and is available to the public and private sector in real time through the MLIT website and its mobile application. Figure 1 shows an example of the spatial distribution of rainfall using two different radar network systems, and clearly shows differences in the spatial distribution of accumulated rainfall.

\section{The challenge of radar-based quantitative precipitation estimation}

Japan has a long history of weather radar observations. A weather radar committee was established in 1950 to promote

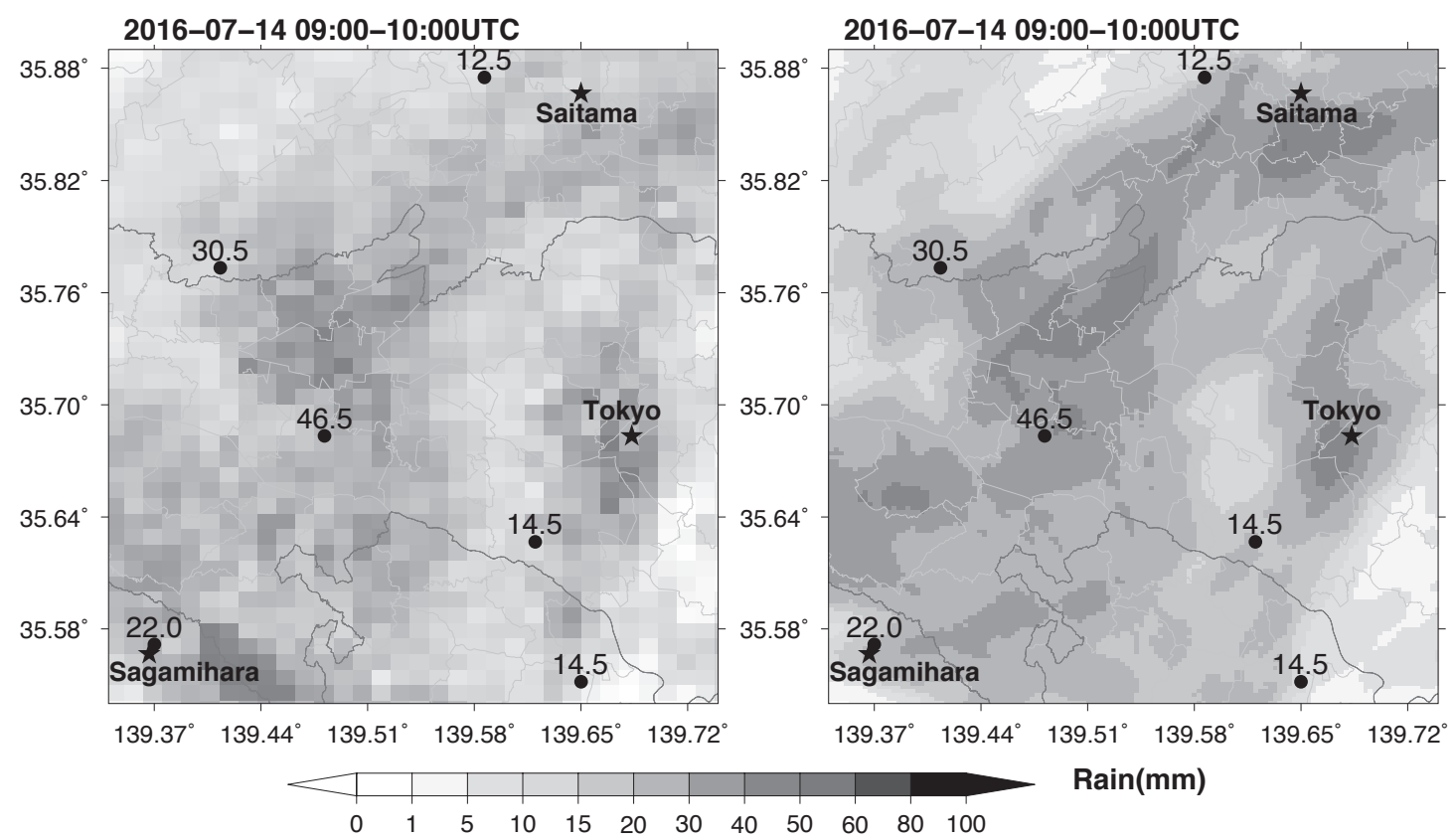

Fig. 1 Spatial distribution of 1-hr accumulated radar rainfall from JMA (left) and MLIT (right) for the period from 0900-1000 UTC 14 July 2016. Black points with numbers indicate 1-hr accumulated rainfall from AMeDAS. 
the introduction of radar technology, and began conducting research using the first X-band weather radar with Plan Position Indicator (PPI) and Range Height Indicator (RHI) indicators. The Japan Radio Company (JRC) built the first Japanese X-band weather radar in 1954. This was installed at the Meteorological Research Institute (MRI) in Tokyo so that it could be compared with the standard C-band radar (Kodaira, and Aoyagi, 1990). Over the period 1950-1970, several studies measured rainfall amounts using different radar systems. The proven effectiveness of these systems in tracking typhoons instigated the deployment of the operational weather radar network in Japan. Since that time, ongoing weather radar observation research for QPE has been conducted throughout Japan, and much progress has been made in this field (Iwanami et al., 2001; Iwanami et al., 2003; Maki et al., 2005; Park et al., 2005; Maesaka et al., 2011; Kim and Maki, 2012; P.C. et al., 2013; P.C. and Maki, 2014).

Weather radar, at C-band, S-band, or X-band wavelengths, is one of the most common technologies used to estimate the spatial and temporal distribution of precipitation over a specific time interval. In Japan, weather radar observations at C-band and X-band wavelengths that incorporate dual polarization technology are most common. Several output parameters can be obtained, including horizontal polarization reflectivity $\left(\mathrm{Z}_{\mathrm{H}}\right)$, vertical polarization reflectivity $\left(\mathrm{Z}_{\mathrm{V}}\right)$, differential reflectivity $\left(Z_{D R}\right)$, and the specific differential propagation phase shift $\left(K_{D P}\right)$, and each has associated benefits and limitations for estimating rainfall rates (Bringi and Chandrashekhar, 2001). C-band radars are most commonly used for operational precipitation estimation, as these systems do not result in as much attenuation as other wavelengths. The application of X-band weather radar to hydrometeorological problems has been described in many studies (Anagnostou et al., 2004; Maki et al., 2005, Matrosov et al., 2005). Research has shown that rain rates derived from $\mathrm{Z}_{\mathrm{H}}$ of $\mathrm{X}$-band polarimetric radar observations compare well with rain gauge data, especially in flat areas (Maki et al., 2005; Park et al., 2005). However, although X-band radar provides high-resolution spatial and temporal rainfall estimates, there are still inherent uncertainties in radar parameters derived from these systems.

The signal attenuation error is a common problem associated with the use of weather radar for QPE (Ryzhkov and Zrnic, 1995; Carey et al., 2000; Anagnostou et al., 2004; Matrosov et al., 2005; Park et al. 2005; Maki et al. 2005; Germann et al., 2006; Kim et al., 2010). Different algorithms have been developed to eliminate the attenuation error for different radar bands in in various environments (Carey et al., 2000; Matrosov et al., 2005; Park et al., 2005; Kim et al., 2010). A significant disadvantage of $X$-band wavelengths is the signal extinction area. If extremely heavy rainfall passes over a radar site, the effective coverage range decreases to less than 10-km (Maki et al., 2012a). This signal extinction problem can be solved by using data from entire radar observation networks (Kim and Maki, 2012). Park et al. (2005) and Kim et al. (2010) corrected for the attenuation effect in the Kanto region of Japan using X-band polarimetric weather data (MP-X Ebina).

Others problems in the use of radar data are beam blockage (mainly over mountainous regions), ground clutter, and anomalous propagation. In general, blockage and ground clutter problems are not as significant over flat areas as over more complex terrain. Vivekanandan et al. (1999) showed that the actual bias in measured reflectivity caused by beam blockage depends on the amount of beam blockage and the reflectivity difference between the precipitation and the ground clutter echo. Therefore, although shielding of the beam over complex terrain is challenging, it is important in producing accurate rainfall estimates (Dinku et al., 2002; Kucera et al., 2004; Germann et al., 2006; Lang et al., 2009). Various direct and indirect methods have been applied to different types of radar to correct errors caused by Partial Beam Blockage (PBB), but there is still no agreement regarding the most appropriate solution, and there have been few studies using $X$-band radar.

The parameter $Z_{\mathrm{H}}$ is widely applied in QPE, and many studies have used it to generate models that closely follow ground-truthed data, especially for light to moderate rain (Park et al., 2005; Kim and Maki, 2012; P.C. et al., 2013). However, radar estimates of rainfall using $\mathrm{Z}_{\mathrm{H}}$ in areas of beam blockage are clearly biased compared with ground-truthed data (Zrnic and Ryzhkov, 1996; Vivekanandan et al., 1999; Kucera et al., 2004; Krajewski et al., 2006; Friedrich et al., 2007; Lang et al., 2009; P.C. et al., 2013). The problem of beam blockage is a major issue affecting radar hydrology and meteorology in mountainous areas. In Japan, there has been limited research into the beam blocking effect. However, as it 
is an important source of error in Japanese radar data because of the presence of complex mountains ranges, I have focused my QPE research on beam blocking conditions. The result was a new algorithm that I have tested in the Hakone mountain region (P.C. et al., 2013), as well as over the Shizuoka and Fujinomiya mountain regions (P.C. and Maki, 2014). This new algorithm shows good agreement with observed data, and I believe that it will help to reduce the beam blocking effect over mountainous regions in Japan.

Other polarimetric parameters, such as $\mathrm{K}_{\mathrm{DP}}$ and $\mathrm{Z}_{\mathrm{DR}}$, may improve the accuracy of QPE (Maki et al., 2005; Park et al., 2005; Matrosov et al., 2005). Friedrich et al. (2007) and Giangrande and Ryzhkov (2004) showed that $\mathrm{K}_{\mathrm{DP}}$ is unaffected by PBB. Therefore, I also analyzed the performance of $\mathrm{K}_{\mathrm{DP}}$ over a beam blocking area. Unfortunately, I did not achieve perfect results, and believe that uncertainty in $\mathrm{K}_{\mathrm{DP}}$ remains high regardless of the maximum percentage of Beam Blockage Rate (BBR). Further research on $\mathrm{K}_{\mathrm{DP}}$ over mountainous regions is therefore needed.

The usefulness of $Z_{\mathrm{DR}}$ has been highlighted previously (e.g., Matrosov et al., 2005). My research has attempted to check the performance on $Z_{\mathrm{DR}}$ under conditions of partial beam blockage. $\mathrm{Z}_{\mathrm{DR}}$ appears to be underestimated during partial beam blockage, and more detailed studies are needed to adjust $Z_{\mathrm{DR}}$ in these cases. Further research will help to produce more accurate values of $Z_{\mathrm{DR}}$ and $\mathrm{K}_{\mathrm{DP}}$ in cases of beam blocking. Combining all of these polarimetric variables will then enhance the quality of radar estimated rainfall over mountainous regions in Japan.

\section{Recent interest in radar rainfall data}

Weather radar observations have recently been highlighted as an alternative option for estimating the spatial and temporal distribution of precipitation across specified time intervals. The application of weather radar for hydrometeorological research in Japan has been described in many studies, but mainly for C-band (Kato and Maki 2009; Shusse et al., 2011; P.C. et al., 2015; Kato et al., 2016) and X-band (Maki et al., 2005; Hirano et al., 2010; Suzuki et al., 2010; Sakurai et al., 2012; Suzuki et al., 2012; Sakurai et al., 2015; Shusse et al., 2015; Shimose et al., 2016) wavelengths. Although C-band meteorological long-range radars are able to monitor rain fields over wide areas, they do not provide a sufficiently high spatial and temporal resolution, and have high purchase and maintenance costs. X-band radars, on the other hand, can be useful for observing rainfall events at higher resolutions. For this reason, the number of $\mathrm{X}$-band dual polarization radar networks is increasing nationwide. However, despite their growing use, beam-shielding problems still exist in X-band systems. Given the growing number of X-band networks, it will be become increasingly important to address this issue. Problems in radar data accuracy are inherent in mountainous regions because of the height, shape, and orientation of mountains. Therefore, PBB correction should be a high priority, especially in a mountainous country like Japan.

Flash floods have become increasingly common in Japan following improvements in river infrastructure, changing runoff, and increased development in headwater catchments. Consequently, it is probable that increased numbers of people in Japan will be exposed to flood events (Hirabayashi et al., 2008; Maki et al., 2012b). Therefore, short-term quantitative precipitation forecasts (QPFs) will become increasingly important in urbanized areas in Japan. To develop a monitoring and prediction system for extreme weather events, the TOMACS (Tokyo Metropolitan Area Convection Study for Extreme Weather Resilient Cities) research project has installed a number of dense meteorological observation networks in collaboration with related government institutions, local government, private companies, and residents (Maki et al., 2012b; Nakatani et al., 2015). One of the key goals of the project is the nowcasting of precipitation. Although rain rates estimated from radar observations provide high-resolution spatio-temporal data for a given area, there are also some uncertainties associated with radar observations (Berenguer and Zawadzki, 2008; P.C. and Maki, 2014; P.C. et al., 2016). In these situations, a single nowcast may be insufficient, and an ensemble of rainfall nowcasts may better address uncertainties. This type of ensemble rainfall nowcast data is desirable for hydrological forecasting of streamflow, and to predict the likelihood of flash floods over small to large watersheds (Moreno et al., 2013).

In general, nowcasting models do not include complex microphysical processes and give little consideration to the highly complex behavior of the atmosphere. Therefore, there is always uncertainty in model outcomes, even if a 
sophisticated algorithm is applied. A new concept known as ensemble nowcasting has been proposed to address the physical uncertainties associated with precipitation nowcasting (Bowler et al., 2006; Berenguer et al., 2011; Seed et al., 2013). This ensemble approach generates a number of forecasts based on the uncertainty of the initial stage of rainfall, and so is able to provide some sense of the likelihood of an event. It is possible to generate a number of realistic future rainfall scenarios using various techniques, and each can be incorporated as an ensemble member within a QPF (Berenguer et al., 2011; Seed et al., 2013). The STEPS (short term ensemble prediction system) model is one of the few models that provides ensemble precipitation nowcasting, and has been tested in a range of countries; e.g., the United Kingdom, Australia, and Belgium. As this approach has yet to be used in Japan, we have little understanding of the impact of ensemble nowcasting on QPF in this region. I have used the STEPS model to produce ensembles of rainfall nowcasts using data obtained from the Japan Meteorological Agency (JMA) weather radar network. The performance of the rainfall nowcast ensemble was tested using observational and JMA precipitation nowcast data. The results and discussion of this research is presented in P.C. et al. (2015).

It should be noted that a wide spread of long echo rain events was used to check the performance of the STEPS model in P.C et al. (2015). The high spatial and temporal resolution radar rainfall data (the XRAIN) in those events were also used in the STEPS model. A comparison using a selected domain (fixed area) inside the study area showed that nowcasting produced similar results to JMA radar. Further investigations focused on convective rain events over mountainous regions in the study area to demonstrate that nowcasting performance over mountainous areas is not as effective as over flat terrain. To minimize nowcasting biases, detailed knowledge is needed of the spatial distribution of weather systems and radar measurement errors. Creating a range of ensemble rainfall nowcasts may present a novel approach to the generation of input data for hydrological modeling and flood forecasting.

\section{Application of weather radar data for hydrological modeling}

The use of accurate information in hydrological models regarding the spatial and temporal variations of rainfall is essential for monitoring river discharge, and may help to improve our understanding of water balances. As previously mentioned, spatial and temporal variations in the amount of precipitation are monitored using limited rain gauge networks with the help of various interpolation techniques. However, interpolation does not always provide a sufficiently precise picture of rainfall distribution. Furthermore, limited and interpolated rain gauge data can introduce large uncertainties into predictions made by hydrological models (Chow et al., 1988). However, point measurements (i.e., rain gauge data) are still widely used for calibration and validation purposes (Price et al., 2014; P.C. et al., 2013; P.C. et al., 2016).

In recent years, weather radar observations have been an alternative option used to estimate the spatial and temporal distribution of precipitation over a specific time interval. Although radar data have been available for almost half a century, operational assimilation has not been widely achieved to date. Many hydrological models have been developed and refined over the past four decades for research and operational purposes (Einfalt et al., 2004; Zhu et al., 2014), and their characteristics must be fully understood if they are to be used effectively. Some models use gridded rainfall data, but their calculated runoff is often output at intervals of greater than $1 \mathrm{hr}$. Such hydrological models are not suitable for monitoring flash floods in urbanized areas. Therefore, hydrologists must continue to familiarize themselves with model classification and understand the theoretical definitions that underlie their operation. Only a few discrete modeling studies have addressed this issue in Japan, and there is much scope for future research.

In general, because of the mountainous terrain, Japanese watersheds have steep slopes, which causes the rapid propagation of flood flows (Tanaka and Tachiakwa, 2014). Many different models have been used to simulate discharge and water level in Japanese rivers (Ando et al., 1983; Lu et al., 1996; Kojima and Takara, 2003; Fujimura et al., 2012; Kobayashi et al., 2016). The application of radar rainfall in hydrological modeling in Japan has been discussed in many studies (e.g., Matsuura et al., 2003; Ichikawa et al., 2003; Yang et al., 2003; 2004; Quang and Lu, 2007; Yu et al., 2015). Hydrological modeling is based on the spatial and temporal relationships among water, weather, soil, and land use. 
Geographic data used in models must have a high spatial resolution. Further, special attention should be given to the spatial and temporal distribution of weather data (i.e., precipitation), because it varies greatly in space and time.

As mentioned in the previous section, high spatial and temporal resolution QPE products are available in Japan. However, there is always uncertainty associated with estimated radar rainfall data for a given area compared with the observed ground-based data (P.C. and Maki, 2014; P.C. et al., 2016). On the other hand, various hydrological models have been used as an alternative to radar data, including physically-based, distributed, lumped, and stochastic models. Each type of hydrological model has its own merits and drawbacks depending on performance and objectives. Uncertainty always exists in the model itself, and this applies to both sophisticated and simple methods (Liu et al., 2007; Goetzinger and Bardossy, 2008; Schroter et al., 2011, Liguori et al., 2012). In general, hydrological model outputs in Japan have produced a precise single deterministic value for each time step. This makes it challenging to compare model outputs with real data because of the uncertainties within the observed or estimated input data, the model itself, or the output data. Probabilistic approaches offer an alternative way to assess simulated data, and may help to address all possible uncertainties so that a more reliable output can be generated. These approaches have been adopted in many countries, and may produce interesting results in Japanese watersheds. However, questions remain about how to make best use of probabilistic information, and how to communicate that information to end users and the public. A solution to this issue will require advanced research with new dimension needs.

\section{Summary}

It has been a great pleasure to have the opportunity to write this commemorative article. I have provided a review of my career history, current research, and some important issues that remain to be addressed in the hydrological and meteorological fields. Several weather radar observation stations have been deployed in Japan for operational as well as research purposes. These remote sensing methods for estimating high-resolution precipitation are some of the most advanced in the world. For example, estimating rainfall at 250-m spatial and 1-mintue time intervals, and to a high degree of accuracy, across all of urbanized Japan is a remarkable achievement. However, although high-resolution spatial and temporal rainfall estimates can be derived from X-band radar, there are several uncertainties inherent in radar parameters that must be considered during the observation period. Scientists and engineers are continuing their research to improve the performance of QPE systems in Japan, and this will enhance the quality of the rainfall data provided in the future.

Radar rainfall data have also been used in hydrological and meteorological fields. One of the most important applications of radar rainfall data is hydrological modeling, which is important for managing and controlling flash floods over urbanized areas. The fine spatial and temporal resolution of radar rainfall data certainly helps to reduce the effects of flash flooding and related disasters. Although there are many different kinds of hydrological model, each output is usually considered in a deterministic way, which might make it difficult to apply the results to flood mitigation efforts. Therefore, presenting hydrological simulation outputs in a probabilistic way could be an important future avenue for research in the Japanese hydrological community.

\section{References}

Allegretti M, Bertoldo S, Prato A, Lucianaz C, Rorato O, Notarpietro R, Gabella M. 2012. X-band mini radar for observing and monitoring rainfall events. Atmospheric and Climate Sciences 2: 290-297.

Anagnostou EN, Anagnostou MN, Krajewski WF, Kruger A, Miriovsky BJ. 2004. High-resolution rainfall estimation from X-band polarimetric radar measurements. Journal of Hydrometeorology 5: 110-128.

Ando Y, Musiake K, Takahasi Y. 1983. Modelling of hydrologic processes in a small natural hillslope basin, based on the synthesis of partial hydrological relationships. Journal of Hydrology 64: 311-337.

Austin GL, Nicol J, Smith K, Peace A, Stow D. 2002. The space time variability of rainfall patterns: implications for measurement and prediction. Western Pacific Geophysics Meeting. AGU: Wellington, H42A-02; wp35.

Barros AP, Joshi M, Putkonen J, Burbank DW. 2000. A study of the 1999 monsoon rainfall in a mountainous region in 
central Nepal using TRMM products and rain gauge observations. Geophysics Research Letter 27: 3683-3686.

Berenguer M, Sempere-Torres D, Pegram G. 2011. SBMcast-An ensemble nowcasting technique to assess the uncertainty in rainfall forecasts by Lagrangian extrapolation. Journal of Hydrology 404: 226-240.

Berenguer M, Zawadzki I. 2008. A study of the error covariance matrix of radar rainfall estimates in stratiform rain. Weather and Forecasting 23: 1085-1101.

Berne A, Delrieu G, Andrieu H, Creutin JD. 200. Influence of the vertical profile of reflectivity on radar-estimated rain rates at short time steps. Journal of Hydrometeorology 5: 296-310.

Bowler NE, Pierce CE, Seed AW. 2006. STEPS: A probabilistic precipitation forecasting scheme which merges an extrapolation nowcast with downscaled NWP. Quarterly Journal of the Royal Meteorological Society 132: 2127-2155.

Bringi VN, Chandraseker V. 2001. Polarimetric Doppler Weather Radar: Principles and Applications. Cambridge University Press, United Kingdom; 636.

Carey LD, Rutledge SA, Ahijevych DA, and Keenan TD. 2000. Correcting propagation effects in C-band polarimetric radar observations of tropical convection using differential propagation phase. Journal of Applied Meteorology 39: 1405-1433.

Chow VT, Maidment DR, Mays LW. 1988. Applied hydrology, McGraw-Hill Series in Water Resources and Environmental Engineering, New York; 572.

Dinku T, Anagnostou EN, Borga M. 2002. Improving radar-based estimation of rainfall over complex terrain. Journal of Applied Meteorology 41: 1163-1178

Einfalt T, Arnbjerg-Nielsen K, Golz C, Jensen NE, Quirmbach M, Vaes G, Vieux B. 2004. Towards a roadmap for use of radar rainfall data in urban drainage. Journal of Hydrology 299: 186-202.

Friedrich K, Germann U, Gourley JJ, Tabary P. 2007. Effects of radar beam shielding on rainfall estimation for the polarimetric C-band radar. Journal of Atmospheric and Oceanic Technology 24: 1839-1859.

Fujibe F, Yamazaki N, Kobayashi K. 2006. Longterm changes of heavy precipitation and dry weather in Japan (19012004). Journal of the Meteorological Society of Japan 84: 1033-1046.

Fujimura K, Shiraha K, Kanae S, Murakami M. 2012. Development of the hourly hydrological model for mountainous basins using the storage function method and the Diskin-Nazimov infiltration model, in: Models -Repositories of Knowledge. IAHS-AISH Publication 355: 338-344.

Georgakakos KP. 2006. Analytical results for operational flash flood guidance. Journal of Hydrology 317: 81-103.

Germann U, Galli G, Boscacci M, Bolliger M. 2006. Radar precipitation measurement in a mountainous region. Quarterly Journal of the Royal Meteorological Society 132: 1669-1692.

Giangrande SE, Ryzhkov AV. 2005. Calibration of dual-polarization radar in the presence of partial beam blockage. Journal of Atmospheric and Oceanic Technology 22: 1156-1166.

Gotzinger J, Bardossy A. 2008. Generic error model for calibration and uncertainty estimation of hydrological models. Water Resources Research 44: W00B07.

Hirabayashi Y, Kanae S, Emori S, Oki T, Kimoto M. 2008. Global projections of changing risks of floods and droughts in a changing climate. Hydrological Sciences Journal 53: 754-772.

Hirabayashi Y, Kanae S. 2009. First estimate of the future global population at risk of flooding. Hydrological Research Letters 3: 6-9.

Hirano K, Maki M. 2010. Method of VIL calculation for X-band polarimetric radar and potential of VIL for nowcasting of localized severe rainfall -Case study of the Zoshigaya downpour, 5 August 2008. SOLA 6: 89-92.

Ichikawa Y, Nakagawa K, Fujiwara K, Shiiba M, Ikebuchi S. 2003. Development of distributed red soil runoff model using radar data. IAHS-AISH Publication 282: 275-281.

Iwanami K, Le Bouar E, Testud J, Maki M, Misumi R, Park SG, Suto M. 2003. Application of the rain profiling algorithm ZPHI to the X-band polarimetric radar data observed in Japan. Preprints 31st Conference of Radar Meteorology, American Meteorological Society: Seattle; 274-276. 
Iwanami K, Misumi R, Maki M, Wakayama T, Hata K, Watanabe S. 2001. Development of a multiparameter radar system on mobile platform. Preprints 30th International Conference of Radar Meteorology, American Meteorological Society: Munich; 104-106.

Kato A, Maki M. 2009. Localized heavy rainfall near Zoshigaya, Tokyo Japan on 5 August 2008 observed by X-band polarimetric radar -Preliminary analysis. SOLA 5: 89-92.

Kato R, Shimizu S, Shimose K, Maesaka T, Iwanami K, Nakagaki H. 2016. Predictability of meso- $\gamma$-scale, localized, extreme, heavy rainfalls during the warm season in Japan using high-resolution precipitation nowcasts. Quarterly Journal of the Royal Meteorological Society (in revision).

Kim DS, Maki M. 2012. Validation of composite polarimetric parameters and rainfall rates from an X-band dualpolarization radar network in the Tokyo metropolitan area. Hydrological Research Letter 6: 76-81.

Kim DS, Maki M, Lee DI. 2010. Retrieval of three-dimensional raindrop size distribution using X-band polarimetric radar data. Journal of Atmospheric and Oceanic Technology 27: 1265-1285.

Kobiyama M, Goerl RF. 2007. Quantitative method to distinguish flood and flash flood as disasters. SUISUI Hydrological Research Letters 1: 11-14.

Kodaira, N, Aoyagi J. 1990. History of radar meteorology in Japan. Radar in Meteorology, Atlas D, Ed., American Meteorological Society 69-76.

Kojima T, Takara K. 2003. A grid-cell based distributed flood runoff model and its performance. IAHS-AISH Publication 282: $234-240$.

Koyabashi K, Otsuka S, Apip, Saito K. 2016. Ensemble flood simulation for a small dam catchment in Japan using 10 and 2 km resolution nonhydrostatic model rainfalls. Natural Hazards and Earth System Science 16: 1821-1839.

Krajewski WF, Ntelekos AA, Goska R. 2006. A GIS based methodology for the assessment of weather radar beam blockage in mountainous regions: Two examples from the U.S. NEXRAD network. Computer \& Geosciences 32: 283302 .

Kubota T, Ushio T, Shige S, Kida S, Kachi M, Okamoto K. 2009. Validation of high-resolution satellite-based rainfall estimates around Japan using gauge-calibrated ground-radar dataset. Journal of Meteorological Society Japan 87: 203-222.

Kucera PA, Krajewski WF, Young CB. 2004. Radar beam occultation studies using GIS and DEM technology: An example study of Guam. Journal of Atmospheric and Oceanic Technology 21: 995-1006.

Lang TJ, Nesbitt SW, Carey LD. 2009. On the correction of partial beam blockage in polarimetric radar data. Journal of Atmospheric and Oceanic Technology 26: 943-957.

Liguori S, Rico-Ramirez MA, Schellart ANA, Saul AJ. 2012. Using probabilistic radar rainfall nowcasts and NWP forecasts for flow prediction in urban catchments. Atmospheric Research 103: 80-95.

Liu YQ, Gupta, HV. 2007. Uncertainty in hydrologic modeling: Toward an integrated data assimilation framework. Water Resources Research 43: W07401.

Lu M, Koike T, Hayakawa N. 1996. A distributed hydrological modeling system linking GIS and hydrological models. IAHS-AISH Publication 235: 141-148.

Maesaka T, Maki M, Iwanami K. 2011. Operational rainfall estimation by X-band MP radar network in MLIT, Japan. Preprints: 35th Conference on Radar Meteorology, September 26-30, 2011 Pittsburgh, USA, 11-142.

Maki M, Iwanami K, Misumi R, Park S, Moriwaki H, Maruyama K, Watabe I, Lee D, Jang M, Kim H, Bringi V, Uyeda H. 2005. Semi-operational rainfall observations with X-band multi-parameter radar. Atmospheric Science Letters 6: 12-18.

Maki M, Maesaka T, Kato A, Kim DS, Iwanami K. 2012a. Composite rainfall map with X-band polarimetric radar network and C-band conventional radar. Indian J Radio Space Phys 41: 461-470.

Maki M, Misumi R, Nakatani T, Suzuki S, Kobayashi T, Yamada Y, Adachi A, Nakamura I, Ishihara M, and TOMACS 
members. 2012b. Tokyo Metropolitan Area Convection Study for Extreme Weather Resilient Cities (TOMACS). 7th European Conference on Radar in Meteorology and Hydrology, June 24-29, 2012 Toulouse, France; 1-6.

Matrosov SY, Kingsmill DE, Martner BE, Ralph FM. 2005. The utility of X-band polarimetric radar for quantitative estimates of rainfall parameters. Journal of Hydrometeorology 6: 248-262.

Matsuura T, Fukami K, Yoshitani J. 2003. Evaluation of the applicability of radar rainfall information to operational hydrology. IAHS-AISH publication 282: 24-29.

Mitra AK, Gupta MD, Singh SV, Krishnamurti TN. 2003. Daily rainfall for the Indian monsoon region from merged satellite and rain gauge values: Large scale analysis from real time data. Journal of Hydrometeorology 4: 769-781.

Moreno HA, Vivoni ER, Gochis DJ. 2013. Limits to flood forecasting in the Colorado front range for two summer convection periods using radar nowcasting and a distributed hydrologic model. Journal of Hydrometeorology 14: 1075-1097.

Nagata K. 2011. Quantitative Precipitation Estimation and Quantitative Precipitation Forecasting by the Japan Meteorological Agency. Technical Review No. 13 RSMC Tokyo-Typhoon Center. 37-50. http://www.jma.go.jp/jma/ jma-eng/jma-center/rsmc-hp-pub-eg/techrev/text13-2.pdf. Last access June 1, 2015.

Nakatani T, Misumi R, Shoji Y, Saito K, Seko H, Seino N, Suzuki S, Shusse Y, Maesaka T, Sugawara H. 2015. Tokyo Metropolitan Area Convection Study for Extreme Weather Resilient Cities (TOMACS). Bulletin of the American Meteorological Society 96: 123-126.

Nesbitt SW, Anders AM. 2009. Very high resolution precipitation climatologies from the Tropical Rainfall Measuring Mission precipitation radar. Geophysical Research Letters 36: L15815.

P.C. S, Maki M, Shimizu S, Maesaka T, Kim DS, Lee DI, lida H. 2013. Correction of reflectivity in the presence of partial beam blockage over a mountainous region using X-band dual polarization radar. Journal of Hydrometeorology 14: 744-764.

P.C. S, Maki M. 2014. Application of a modified digital elevation model method to correct radar reflectivity of X-band dual-polarization radars in mountainous regions. Hydrological Research Letters 8: 77-83.

P.C. S, Misumi R, Nakatani T, Iwanami K, Maki M, Seed AW, Hirano K. 2015. Comparison of rainfall nowcasting derived from the STEPS model and JMA precipitation nowcasts. Hydrological Research Letters 9: 54-60.

P.C. S, Misumi R, Nakatani T, Iwanami K, Maki M, Maesaka T, Hirano K. 2016. Accuracy of quantitative precipitation estimation using operational weather radars: a case study of heavy rainfall on 9-10 September 2015 in the East Kanto Region, Japan. Journal of Disaster Research 11: 1003-1016.

Park SG, Maki M, Iwanami K, Bringi VN, Chandrasekar V. 2005. Correction of radar reflectivity and differential reflectivity for rain attenuation at $\mathrm{X}$ band. Part II: Evaluation and application. Journal of Atmospheric and Oceanic Technology 22: 1633-1655.

Price K, Purucker ST, Kraemer SR. 2014. Comparison of radar and gauge precipitation data in watershed models across varying spatial and temporal scales. Hydrological Processes 28: 3505-3520.

Quang CNX, Lu M. 2007. Applicability of the neural network based radar rainfall estimation in streamflow modeling. Journal of Japan Society of Hydrology and Water Resources 20: 191-200.

Ryzhkov A, Zrnic DS. 1995. Precipitation and attenuation measurements at a 10-cm wavelength. Journal of Applied Meteorology 34: 2121-2134.

Sakurai N, Iwanami K, Maesaka T, Suzuki S, Shimizu S, Misumi R, Kim DS, Maki M. 2012. Case Study of Misoscale Convective Echo Behavior Associated with Cumulonimbus Development Observed by Ka-band Doppler Radar in the Kanto Region, Japan. SOLA 8: 107-110.

Sakurai N, Shimizu S, Shusse Y, Suzuki S, Maesaka T, Kieda K, Iwanami K. 2015. Relationships between updraft characteristics and cloud-to-ground lightning activity in warm-season convective storms in the Kanto Region, Japan. SOLA 11: 177-180.

Schroter K, Llort X, Velasco-Forero C, Ostrowski M, Sempere-Torres D. 2011. Implications of radar rainfall estimates 
using uncertainty on distributed hydrological model predictions. Atmospheric Research 100: 237-245.

Seed AW, Pierce CE, Norman K. 2013. Formulation and evaluation of a scale decomposition-based stochastic precipitation nowcast scheme. Water Resources Research 49: 6624-6641.

Shimose K, Shimizu S, Maesaka T, Kato R, Kieda K, Iwanami K. 2016. Impact of observation operators on low-level wind speed retrieved by variational multiple-doppler analysis. SOLA 12: 215-219.

Shusse, Y, Takahashi N, Nakagawa K, Satoh S, Iguchi T. 2011. Polarimetric radar observation of the melting layer in a convective rainfall system during the rainy season over the East China Sea. Journal of Applied Meteorology and Climatology 50: 354-367.

Shusse, Y, Maki M, Shimizu S, Iwanami K, Maesaka T, Suzuki S, Sakurai N, Misumi R. 2015. Relationship between precipitation core behavior in cumulonimbus clouds and surface rainfall intensity on 18 August 2011 in the Kanto Region, Japan. Journal of Meteorological Society Japan 93: 215-228.

Strangeways I. 2004. Improving precipitation measurement. International Journal of Climatology 24: 1443-1460.

Sugiura I. 2013. Very-short-range forecast of precipitation in Japan. 14th annual WRF users's workshop. 24-28 June 2013, Colorado, USA.

Suzuki S, Iwanami K, Maesaka T, Shimizu S, Sakurai N, Maki M. 2012. Observations of hailstorms by X-band dual polarization radar. Hydrological Sciences Journal 351: 415-420.

Suzuki S, Maesaka T, Iwanami K,Misumi R, Shimizu S, Maki M. 2010. Multi-parameter radar observation of a downburst storm in Tokyo on 12 July 2008. SOLA 6: 53-56.

Tanaka T, Tachikawa Y. 2014. Testing the applicability of a kinematic wave-based distributed hydrologic model in two climatically contrasting catchments. Hydrological Sciences Journal 60: 1361-1373.

Vivekanandan J, Yates DN, Brandes EA. 1999. The influence of terrain on rainfall estimates from radar reflectivity and specific propagation phase observations. Journal of Atmospheric and Oceanic Technology 16: 837-845.

Yang D, Koike K, Tanizawa H. 2003. Effect of precipitation spatial distribution on the hydrological response in the upper Tone River of Japan. IAHS-AISH Publication 282: 194-202.

Yang D, Koike T, Tanizawa H. 2004. Application of a distributed hydrological model and weather radar observations for flood management in the upper Tone River of Japan. Hydrological Processes 18: 3119-3132.

Yu W, Nakakita E, Kim S, Yamaguchi K. 2015. Improvement of rainfall and flood forecasts by blending ensemble NWP rainfall with radar prediction considering orographic rainfall. Journal of Hydrology 531: 494-507.

Zhu D, Xuan Y, Cluckie I. 2014. Hydrological appraisal of operational weather radar rainfall estimates in the context of different modelling structures. Hydrology and Earth System Science 18: 257-272.

Zrnic DS, Ryzhkov A. 1996. Advantages of rain measurements using specific differential phase. Journal of Atmospheric and Oceanic Technology 13: 454-464.

\section{Biography - Dr. Shakti P.C.}

Dr. Shakti P.C. has been an associate research fellow at the Storm, Flood and Landslide Research Division, National Research Institute for Earth Science and Disaster Resilience (NIED) since 2013. He completed his PhD in geoenviromental science from the Graduate School of Life and Environmental Science, University of Tsukuba in 2013. His hometown is Sandhikharka-6, Arghakhanchi, Lumbini Zone, Nepal. He received an MSc in meteorology with top ranking (gold medalist) from the Center Department of Hydrology and Meteorology, Tribhuvan University (TU), Kathmandu, Nepal, in 2003. After receiving his master's degree, he lectured at TU, Kathmandu until 2007 and oversaw the BSc environmental program at Khwopa College, TU, Nepal. In 2007, he moved to Belgium to study in the Interuniversity Program in Water Resources Engineering, and completed a 2-year Master of Water Resources Engineering (IUPWARE) with a full scholarship from the Flemish Interuniversity Council (VLIR-UOS). After completing his master's, he returned to Nepal and worked for an NGO before moving to Japan in 2010 to begin PhD research. 
Dr. Shakti P.C. was a recipient of the Mahendra Bidhya Bhusan "Kha" for achieving the highest mark in his master's course. He was also awarded various scholarships at undergraduate and postgraduate level. He is a lifetime member of the Society of Hydrologists and Meteorologists -Nepal (SOHAM). He is also member of the Japan Society of Hydrology and Water Resources (JSHWR) and the Japan Geophysical Union (JpGU). He has published several research papers in international peer reviewed journals, has been regularly invited to give lectures in this field, and regularly participates in international and national conferences to talk about his research. He has served as a reviewer for Hydrological Research Letters. 